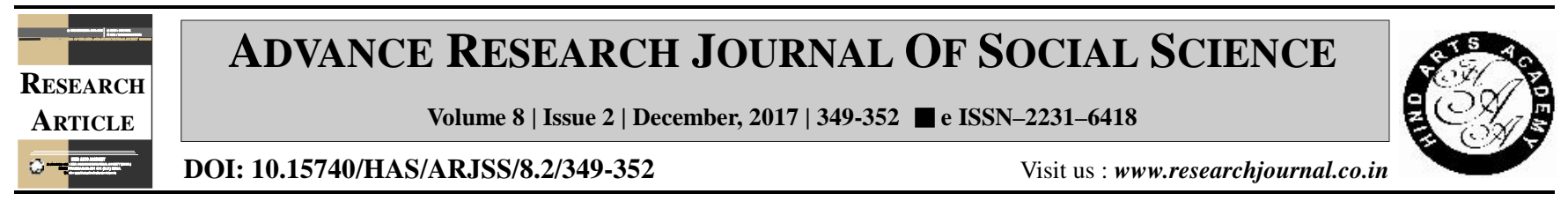

\title{
Influence of locale over guardians' and school teachers' opinion towards mid-day meal programme
}

\author{
Anita Singh* and Smita Singh
}

Department of Home Science, Sri Agrasen Kanya P.G. College (Autonomous College), Parmanandpur, VARANASI (U.P.) INDIA

\section{ARTICLE INFO :}

$\begin{array}{lll}\text { Received } & : & 14.10 .2017 \\ \text { Revised } & : & 07.11 .2017 \\ \text { Accepted } & : & 20.11 .2017\end{array}$

\section{KEY WORDS :}

Mid day meal (MDM), Opinionnaire, Critical ratio, Degree of freedom, Stratified random sampling

\section{HOW TO CITE THIS ARTICLE :}

Singh, Anita and Singh, Smita (2017). Influence of locale over guardians' and school teachers' opinion towards mid-day meal programme. Adv. Res. J. Soc. Sci., 8 (2) : 349-352, DOI: 10.15740/HAS/ ARJSS/8.2/349-352.

*Author for correspondence

\begin{abstract}
The present study was undertaken to see the influence of locale over guardians and teachers opinion towards mid day meal scheme. By using descriptive survey method the task got accomplished on a sample of two hundred fifty, selected from district Varanasi (U.P.). Here stratified random sampling technique was used to find a representative data. Keeping in view the objectives of study a self structured tool opinionnaire was developed on three points with thirty items on Likert pattern. The data were collected by administering the opinionnaire on guardians and basic school teachers both belonging to urban and rural locale. The raw scores so obtained were analysed objective wise through null hypothesis on all the six domains of mid day meal programme. Domain wise mean opinion differences were assessed through two tailed test of significance Depending upon comparable groups critical ratio values were calculated and there after significance was marked only when ' $t$ ' value exceeded by standard values (C.R.- 1.98 for 0.05 and 2.62 for 0.01 level). In capsule the overall assessment revealed that guardians opinion towards mid day meal is not influenced by urban or rural locale, although in limited perspective specially in domain variety, quality and pitfalls rural locale significantly showed more favourable opinion. As regards teacher's group, basic school teachers' opinion under the domains variety and quality as well as merits were found more favourable than those of urban counterparts. Apart, the opinion of urban basic school teacher's with respect to attendance and enrollment was found more favourable when compared with those of rural counterparts. In over all assessment the basic school teachers from rural locale with ' $t$ ' value 3.01 at 0.01 level of significance against 123 degree of freedom were found to have opinion more favourable when compared with counterparts belonging to urban background and thus the influence of locale over opinion is inferred to be real and not by chance
\end{abstract}

